\title{
Assessments of Sexual Practices and Khat Chewing Habits Among Dire Dawa University Students, Eastern Ethiopia
}

\author{
Wondu Teshome Beharu \\ College of Social Science and Humanities, Dire Dawa University \\ P. O. Box: 1362, Dire Dawa, Ethiopia
}

\begin{abstract}
The purpose of this study was to examine the sexual practices, experiences and khat chewing habits among Dire Dawa university students. The participants of the study were 201 under graduate students selected from Dire Dawa University. The sample of study was taken through stratified and simple random sampling techniques. To collect the data, questionnaires and scales were used. The data was analyzed and interpreted by both descriptive and inferential statistical methods. The study shows that the sexual practices of the respondents having sex with uncommitted partners $136(67.7 \%)$ was the higher response for sexual practices and having sex before discussing risk factors 131 (65.2) and sex under the influence of khat chewing 82 (40.8\%) were reported by the study participants. The study shows that the sexual experiences of the respondents having sexual intercourse after joining campus life was $81(40.3 \%)$ and whereas the majority $120(59.7 \%)$ of them reported that they have sexual experiences before joining campus. The study participants stated a number of reasons for khat chewing habits such as to increase academic performance and religious practices were mentioned by $44.3 \%$ and $14.4 \%$ of study participants respectively. There is a positive correlation between students' khat chewing score and sexual practice, $\mathrm{r}=.774, \mathrm{n}=201, \mathrm{p}<.000$, with sexual experience, $\mathrm{r}=.459, \mathrm{n}=201, \mathrm{p}<.000$. This study finding showed that from the total respondents about $77.1 \%$ of the respondents reported they had experienced khat chewing. Khat chewing is associated with sexual practices and sexual experiences of students. As such, treatment and prevention measures are needed to prevent the students from engaging in khat chewing habits which may lead towards risky sexual behaviors.
\end{abstract}

Keywords: Sexual Practices; Khat Chewing Habits; University Students.

DOI: $10.7176 /$ RHSS/10-5-06

Publication date:March $31^{\text {st }} 2020$

\section{INTRODUCTION}

HIV/AIDS is one of the greatest problems faced by human nature. This problem is one of the most global issues in the world wide. It is in Africa, the poorest countries in the world that the impact of HIV/AIDS has been more severe. The rate of HIV infection is still extremely high in sub-Saharan Africa, where one-tenth of the adult population aged 15-49 was infected with HIV. This means that there are now an estimated 22.5 million Africans living with HIV/AIDS. In this part of the world, particularly, women are disproportionately at risk. It is widely thought that North Africa managed to side step the global AIDS epidemic, perhaps due to its restrict rules governing sexual behavior (NASTAD, 2013). In Ethiopia, young people, including university students, are engaging in sexually risky behaviors which increase their likelihood of acquiring HIV/AIDS. High risk sexual behaviors have been reported among university and high school students (CDC, 2012).

Study conducted in Ethiopia have shown that those engaging in sexual contact report multiple partners, inconsistent and incorrect condom use, and having lifetime history of chewing khat, having extra sexual partners, watching pornographic film and drug abuse was significantly associated with sexually transmitted infections and the likelihood of contracting HIV/AIDS (Abate et al.,2018; Kebede et al., 2018). Since the majority of Ethiopian universities have only recently been established, most university officials have not yet made HIV and STI prevention a priority and have little experience implementing HIV and STI prevention, despite these being environments that expose students to greater opportunities and circumstances that increase risky behavior. The current study by Kebede et al. (2018), indicate that interventions in the universities have focused on abstinence as policy but, abstinence by itself does not work. Their study indicated that among university students, $64.4 \%$ ever had a practice of sex with multiple sexual partners and $83.5 \%$ use condom inconsistently. This shows as limiting sexual practices and not availing condom and other services do not hamper the students from performing sexual intercourse anywhere else unless their behavior is modified.

A cross sectional study conducted by NASTAD (2013), estimate HIV prevalence among Dire Dawa University students and assess behaviors that may contribute to risk of HIV infection was conducted and out of 966 students participating, 960 (99.4\%) were tested for HIV and (0.4\%) were HIV positive. Fifty percent of participants reported ever having sex and 53.0\% reported having sex in the past 12 months. Females were more likely to report first having sex after coming to the university and not having used a condom during their first sexual intercourse, and males were more likely to report sex with two or more partners in the past 12 months and having used alcohol in the past month (NASTAD, 2013). Information on university students' HIV risk behaviors 
could inform efforts to prevent new HIV infections among young people in Ethiopia.

On the other hand, the study conducted by Gemechis, Atinafu, Bedasa and Dagne (2017) on psycho-active substances use and determining factors among regular undergraduate students of Dire Dawa University indicate that the top three psycho-active substances used in last twelve months by students were alcohol (60\%), khat (59.9\%) and tobacco $(56.5 \%)$. This study also indicate that the prevalence of alcohol, khat, tobacco and cannabis products use in past thirty days was $60 \%, 59.6 \%, 41.2 \%$ and $13.7 \%$ respectively. As such, based on the above crucial research information in mind, it is fruitful to design such preventive projects for higher education institution in general and Dire Dawa university in particular to tackle and mitigate risk behavior and drug addiction among students.

In recent years, researchers have begun to investigate human sexuality in various aspects of human life. They are beginning to understand differences in sexual behaviors' among various social groups. However, the review of 25 sexuality research by Strong, et al. (2002) revealed that there is a deficit in empirical investigations as a result of socio-cultural variations. These include the difference that socio economic status and environment can create a big role in sexual behavior. As such, the physical and social environment with in Dire Dawa city might also play crucial role on shaping the sexual behaviors of students in Dire Dawa University. The widely available cash crop known as the "Eastern Ethiopian Mercury" or Khat from the surrounding Hararghe highlands might make Dire Dawa number one for drug and alcohol abuse. Moreover, the "Queen City of the Desert" (Dire Dawa) may enable students who join this university from every corner of the country to be attracted and influenced in the surrounding social processes.

According to Deribachew, H. and Kanchi, M. (2015), Khat is one of the shrub plants with an amphetaminelike stimulant effect. Khat use occurs in all segments of all societies, which results in decreased work and school performance, and absenteeism. Khat is being chewed as a habit in some African countries such as Ethiopia, Somalia, Kenya, and Yemen. Moreover, the habit is now being introduced into different countries of the world (Numan, N. 2012). In Eastern Ethiopia, chewing khat is common and becoming an every-day social drug which sold and bought in cities such as Dire Dawa and Harar in Eastern Ethiopia. According to Kebede, Y. (2002), the re is a strong link between chewing khat, taking excess alcohol, unsaved sexual practice among college students in North West Ethiopia. The habit of chewing Khat is spreading at an alarming rate among the younger generation of Ethiopian, especially in high schools and higher institutions, where academic activity is intense (Deribachew, H. and Kanchi, M. 2015).

According to Ethiopian Demographic and Health Survey (EDHS, 2005) among women age 25-49 years, 32\% had sexual intercourse before age 15 years, $65 \%$ before age 18 years, and by age

25 years most Ethiopian women have had sexual intercourse. Considering students deep sexual behavior, it is hardly surprising that there is a great deal of confusion about the problems of sexual behavior and what to do about this situation. Today more than ten thousand regular students found in Dire Dawa University and the number of students who join this university also increasing in alarming rate each year. However, beyond the teachinglearning processes in this University, the problem of risky behavior is expected due to lack of sex education in the curriculum, access to training and counseling service not yet adequate for this students in the campus.

A study conducted by Rahel et al. (2003) revealed that the percentage of young women and men age 15 to 24 in Ethiopia, who had sex before age 15 are 41.5 percent and 40.3 percent respectively. Most studies stated that age is an important factors for sexually risky behavior that causes HIV infection which widely spread in most developing countries likes Ethiopia As such, in most higher institutions in Ethiopia, the age of students mostly classifies between 15 to 25 is highly expected. This age range is remarkably forced a high numbers of youngsters to be a victims of sexually risky be heavier as a result of peer pressure, alcohol and drug abuse. Most students who used to take alcohol and other drug could not protect themselves from unwanted sexual act. Using alcohol, khat, tobacco and other psycho-active substances by youths are harmful. They make students to have decreased academic performance, to get HIV and other sexually transmitted diseases. Moreover, the problem of sexually risky behaviors and Khat chewing habits among students in this university where neglected and expanded extremely and rapidly in alarming rate. Therefore, having the above back ground in mind, this study tries to assess sexual practices and the culture of khat chewing habits and what it look like in current trends among Dire Dawa University students.

Ethiopia is undergoing higher education expansion and reform programs in dimensions like establishing new universities, introducing new courses, and increasing the enrollment rate of students. With clear understanding, the numbers of universities in Ethiopia are increasing with increasing number of student population, among which Dire Dawa University is one. The number of students is increased simultaneously, accompanied by tremendous psycho-social problems. Risky sexual behavior, unwanted pregnancy and abortion, gender violence, stress, academic failure, predisposing factors such as psychoactive drug addiction, and alcoholism may increase vulnerability of students to HIV infection. These factors are emerging and might be due to the age of the students (that is, puberty age), background of the students (either academic or social problems), absence of reproduction health education including HIV and AIDS and other sexually transmitted diseases; all of these factors need holistic 
interventions. Having the above facts in mind, the objective of this study is to assess potential risky sexual behaviors and substance abuse particularly khat chewing habits among Dire Dawa University undergraduate students.

Above all, since the current trend of the country's toward preventing HIV/AIDS at all level of social institutions in agreement with the government policy. Moreover, this project create its share in creating safe environment where students to be save themselves and their community from such problem to lead healthy life and productivity of the country on all areas. As such, this study will serve the students of higher education institution in general and Dire Dawa University on particular by preventing sexually risky behaviors and Khat abuse among students.

The main aims and objectives of this study is the following:

(1) To assess the sexual practices and experiences of students in Dire Dawa University.

(2) To identify factors associated with Khat chewing habits among Dire Dawa University students.

(3) To finds out the relationships between Khat chewing and sexual practices among Dire Dawa University students.

\section{METHODS}

\section{Study Design}

The purpose of this study is to investigate the sexual practices and khat chewing habits among Dire Dawa university students. Thus, a cross-sectional design with quantitative approaches was selected.

\section{Study Population}

The study was undertaken in Dire Dawa University undergraduate regular students from College of Natural and Computational Science among four departments namely Biology, Chemistry, Mathematics and Physics.

\section{Samples and Sampling Techniques}

The study sample was taken from regular students from Dire Dawa Universities who enrolled in undergraduate program in 2018/19 academic year. Specifically, under graduate students from college of natural and computational sciences who were at academic level of $2^{\text {nd }}$ year and above. Each department was treated as a stratum and therefore stratified random sampling was employed. In order to determine a representative sample size for this study population, a standard formula developed by Kurtz (1983) was used. The researchers applied the correction factor adjustment formula to draw the actual sample size from the finite student population. The following assumptions were adopted from Kurtz (1983) in order to draw the representative sample size. In order to obtain the maximum sample size, and based on the assumption of maximum heterogeneity or maximum variation sampling, the estimate of the population (p) was assumed to be 50\% (.50). The maximum allowable error $(E)$ was assumed to be $5 \%=.05$. The standard normal value corresponding to the desired level of confidence $(\mathrm{z})$, or a confidence interval of $95 \%$, was assumed $(z=1.96)$. Based on this formula the sample size of this study was 201 participants from Dire Dawa University.

Table1: Sample Population of the Study, Dire Dawa University, (2019)

\begin{tabular}{|l|l|l|l|l|l|l|l|l|l|}
\hline University & College & Departments & Year & Population & & & Samples & & \\
\hline DDU & CNCS & & & Male & Female & Total & Male & Female & Total \\
\hline & & Biology & $2^{\text {nd }}$ Year & 33 & 52 & 85 & 16 & 25 & 41 \\
\hline & & & $3^{\text {rd }}$ Year & 59 & 37 & 96 & 28 & 18 & 46 \\
\hline & & Chemistry & $2^{\text {nd }}$ Year & 24 & 19 & 43 & 11 & 9 & 20 \\
\hline & & & $3^{\text {rd }}$ Year & 46 & 17 & 63 & 22 & 8 & 30 \\
\hline & & Mathematics & $2^{\text {nd }}$ Year & 29 & 15 & 44 & 14 & 7 & 21 \\
\hline & & & $3^{\text {rd }}$ Year & 15 & 19 & 34 & 7 & 9 & 16 \\
\hline & & Physics & $2^{\text {nd }}$ Year & 20 & 6 & 26 & 9 & 3 & 12 \\
\hline Total & & & $3^{\text {rd }}$ Year & 12 & 21 & 33 & 5 & 10 & 15 \\
\hline
\end{tabular}

\section{Sample selection}

The selection technique utilized is probability sampling. The Sample for the quantitative analysis was four departments from year two and above only.

\section{Inclusion Criteria}

Only undergraduate students.

Regular students $2^{\text {nd }}$ year and above were selected for the study.

Students only from natural science in four departments were selected for the study.

\section{Procedures}

The data collection process takes place during April, 25, 2019 up to May, 17, 2019. First official letters were written for me from Addis Ababa University, school of psychology and taken to the college deans and gain permission for data collection. Then the researcher give a thoroughly orientation to participant students regarding 
ethics, objective and value of research. Finally, they were asked to fill the questionnaires carefully. Participation in the study was voluntary and all questionnaires were completed anonymously.

\section{Materials}

The data collection instruments were questionnaires. The questionnaire was designed to achieve the purpose of this study. The Questionnaires were adopted and modified from previous studies published on reputable journals such as Gezahegn Tesfaye, Andualem Derese, and Mitiku Teshome (2014), substance use and associated factors among University Students in Ethiopia and Jessica, A., Turchik, and John P. Garske (2008), Measurement of Sexual Risk Taking Among College Students. Furthermore, pilot study was carried out to check the validity and reliability of the instruments. The sexual practices, experiences and Khat chewing habit survey statements were designed with various responses the majority of the items designed via "Yes" and "No" rating scales.

\section{Methods of Data Analysis}

The data were analyzed using descriptive statistics such as frequencies, percentage, mean, standard deviation were computed first. Then, to investigate the relationship between variables, Pearson correlation coefficient was employed. The analysis was performed by using the Statistical Package for Social Science (SPSS) version 24.0 with test of significance with alpha 0.05. In this study, (age, sex, religion, Khat chewing, academic status and field of study) were treated as independent variable whereas Sexual Practice Scales (SPS) \& Sexual Experience Scale (SES) were treated as dependent variable. The study variables coded and entered into SPSS as follow:

Table-2: The Coding Instructions of the Study Variables, Dire Dawa University, (2019)

\begin{tabular}{|c|c|c|}
\hline $\begin{array}{l}\text { Variables } \\
\text { Name }\end{array}$ & SPSS Variable Name & Coding Instructions \\
\hline Age & Age & $2=23-25$ \\
\hline Sex & Sex & $2=$ Female \\
\hline Religion & Religion & $1=$ Christians; \\
\hline Money & Monthly Pocket Money & $1=50-200 ; 2=201-300 ; \quad 3=301-400 ; \quad 4=401+$ \\
\hline Khat & Khat Chewing Habits & $1=$ Yes \\
\hline Intercourse & Sexual Intercourse Habits & $\begin{array}{ll}\text { 1=Always }(\mathrm{A}) ; & 2=\operatorname{Sometimes}(\mathrm{S}) ; \\
3=\text { Rarely }(\mathrm{R}) & 4=\operatorname{Never}(\mathrm{N})\end{array}$ \\
\hline Fields & Fields of Study & 1=Biology; 2=Chemistry; 3=Mathematics; 4=Physics \\
\hline Academic & Academic Levels & $1=$ Second year; \\
\hline SPS1 to SPS8 & Sexual Practice Scale & $1=$ Yes \\
\hline $\begin{array}{ll}\text { SES1 } & \text { to } \\
\text { SES10 } & \\
\end{array}$ & Sexual Experience Scale & $1=$ Yes \\
\hline Reasons & Reason for Chewing Khat & $\begin{array}{l}1=\text { To increase academic performance, } 2=\text { To get personal } \\
\text { pleasure, } 3=\text { To get relief from tension, } 4=\text { To stay awake, } 5=\text { Due } \\
\text { to peer influence, } 6=\text { To get acceptance by others, } 7=\text { To be } \\
\text { sociable, } 8=\text { Due to religious practice, } 9=\text { others }\end{array}$ \\
\hline
\end{tabular}

\section{RESULTS}

The sample consisted of 201 undergraduate students, ranging in age from 18 to 35 years. Participants gender composition indicate that one-hundred-twelve $112(55.7 \%)$ of the sample were males, and eight nine $89(44.3 \%)$ of the sample were females. The religion of the study participants indicate that $120(59.7 \%)$ of the sample were Christians and the rest $81(40.3 \%)$ of the sample were Muslim. Regarding participants field of study, 87 (43.3\%) were from Biology, 50 (24.9\%) were from Chemistry, 37 (18.4\%) were from Mathematics and $27(13.4 \%)$ were from Physics field of study. The academic status (levels) of participants indicated that 107 (53.2\%) were third year and $94(46.8 \%)$ were second year. With regard to monthly income, the majority $59(29.4 \%)$ of the respondents earns 50-200 Ethiopian Birr (ETB) per month. Whereas, 52 (25.9\%) and 39 (19.4\%) were earns from 201-400 ETB per month and the rest $51(25.4 \%)$ of the respondents were earns more than 401 ETB per month.

\section{Khat Chewing Habits among Dire Dawa University Students}

As the findings of the study indicated that from both sexes the majority of the participants were engaged in khat chewing activities in their campus life. As indicated in table-1 below, forty five percents of male and thirty two percents of female were chew khat during their university studies.

Table-1: Respondents Khat Chewing Habits, Dire Dawa University, $2019(\mathbf{n}=\mathbf{2 0 1})$

\begin{tabular}{lllll}
\hline \multicolumn{5}{l}{} \\
\multicolumn{2}{l}{ Variables } & \multicolumn{2}{l}{ Khat Chewing Habits } & Total \\
\hline Sex & Male & $31(16.3 \%)$ & $81(45.1 \%)$ & $112(61.4 \%)$ \\
& Female & $15(6.6 \%)$ & $74(32.0 \%)$ & $89(38.6 \%)$ \\
\hline Total & $46(22.9 \%)$ & $155(77.1)$ & $201(100 \%)$ \\
\hline
\end{tabular}

The khat chewing habits by respondents was assessed with respect to whether chewing chat is their habits or 
not. This study finding showed that from the total respondents about $77.1 \%$ and $22.9 \%$ of the respondents reported they had experienced chewing khat and no experience of chewing khat respectively (Table-1). Forty five percent of the respondents were male and thirty two percent of the respondents were female among the khat chewers among these, the majority (77.1\%) were current khat chewers. According to Habtamu Teklie, et al. (2015) a large proportion $(49 \%)$ of the participants who ever chewed khat were from Harari region followed by Dire Dawa (35.3\%), Somali (35.2\%) and Oromia (34.5\%) regions respectively. According to this study, an overall prevalence of current khat chewing rate of $15.8 \%$ (21.1\% of males and $9.4 \%$ of females) across the country. According to Abate et al. (2018), out of the total 794 study participants, $204(25.7 \%)$ had a history of chewing khat at least once in their life; of them, $79.9 \%$ had the history of chewing in the last 12 months. About 95 percent of those who chewed in the last 12 months practiced khat chewing within last 3 months.

\section{Practiced Sexual Intercourse Habits among Dire Dawa University Students}

Out of the total respondents, $66(32.8 \%)$ of students had sexual practice habits. From the total respondents who had practiced sexual intercourse $54(26.9 \%)$ of them reported that their first sexual intercourse was occurred occasionally while $44(21.9 \%)$ of them had their sexual intercourse sometimes. The rest of the respondents with sexual experience $24(11.9 \%)$ and $13(6.5 \%)$ has practiced sexual intercourse rarely and never respectively (Table2).

Table-2: Respondents Sexual Intercourse Habits, Dire Dawa University, 2019 (n= 201)

\begin{tabular}{lll}
\hline Sexual Intercourse Habits & Frequency & Percent \\
\hline Always & 66 & 32.8 \\
\cline { 2 - 3 } Sometimes & 44 & 21.9 \\
\hline Occasionally & 54 & 26.9 \\
\hline Rarely & 24 & 11.9 \\
\hline Never & 13 & 6.5 \\
\hline Total & 201 & 100.0 \\
\hline
\end{tabular}

Factors Associated with Khat Chewing Habits among Dire Dawa University Students

The study participants stated a number of reasons for practicing in khat chewing. These included factors such as to increase academic performance and religious practices were mentioned by $44.3 \%$ and $14.4 \%$ of study participants, respectively (Table-3). Out of the respondents, $20(10 \%)$ of the respondents revealed chewing khat to be sociable with their friends and $14(7 \%)$ revealed that to get accepted by others. Whereas, $12(6 \%)$ to stay awake for their study and $11(5.5 \%)$ chew khat as a results of peer influence.

Table-3: Respondents Reasons for Khat Chewing, Dire Dawa University, 2019 (n= 201)

\begin{tabular}{lll}
\hline Reasons for Khat Chewing & Frequency & Percent \\
\hline To increase academic performance & 89 & 44.3 \\
\hline To get personal pleasure & 8 & 4.0 \\
\hline To get relief from tension & 10 & 5.0 \\
\hline To stay awake & 12 & 6.0 \\
\hline Due to peer influence & 11 & 5.5 \\
\hline To get acceptance by others & 14 & 7.0 \\
\hline To be sociable & 20 & 10.0 \\
\hline Due to religious practice & 29 & 14.4 \\
\hline Others & 8 & 4.0 \\
\hline Total & 201 & 100.0 \\
\hline
\end{tabular}

Sexual Practices and Experiences among Dire Dawa University Students

As depicted in Table- 4 below, the descriptive statistics of the study shows that the sexual practices of the respondents having sex with uncommitted partners $136(67.7 \%)$ was the higher response for sexual practices and sex before discussing risk factors131 (65.2) and Sex under the influence of khat chewing 82 (40.8\%). Regarding Sex without a condom $155(77.1 \%)$ revealed that no sex without condom whereas $46(22.9 \%)$ of the respondents only did sex without a condom. Out of the respondents, $52(25.9 \%)$ reported that they did sex with someone doesn't know well and whereas, the majority of the respondents, $149(74.1 \%)$ they did not commit sex with someone doesn't know well. 
Table-4: Respondents Sexual Practices, Dire Dawa University, 2019 (n= 201)

\begin{tabular}{llll}
\hline Variables & $N$ & $Y e s$ & No \\
\hline Sex with uncommitted partners & 201 & $136(67.7)$ & $65(32.3)$ \\
\hline Sex with someone doesn't know well & 201 & $52(25.9)$ & $149(74.1)$ \\
\hline Sex before discussing risk factors & 201 & $131(65.2)$ & $70(34.8)$ \\
\hline Sex with untested partner & 201 & $54(26.9)$ & $147(73.1)$ \\
\hline Sex without a condom & 201 & $46(22.9)$ & $155(77.1)$ \\
\hline Sex under the influence of khat chewing & 201 & $82(40.8)$ & $119(59.2)$ \\
\hline Sex with someone with many partners & 201 & $49(24.4)$ & $152(76.6)$ \\
\hline Sex with acquaintance & 201 & $77(38.3)$ & $124(61.7)$ \\
\hline
\end{tabular}

As depicted in Table-5 below, the descriptive statistics of the study shows that the sexual experiences of the respondents having sexual intercourse after joining campus life was $81(40.3 \%)$ and whereas the majority 120 $(59.7 \%)$ of them reported that they have sexual experiences before joining campus. Out of the total respondents, $155(77.1 \%)$ of students had no sexual intercourse with more than one partner whereas, $45(22.4 \%)$ of students had sexual intercourse with more than one partner. Surprisingly, in the past 12 months, $126(62.7 \%)$ of respondents did not use of condom during sexual intercourse and only $76(37.8 \%)$ of respondents use condom during sexual intercourse. Out of the respondents, the majority, $127(63.2 \%)$ of them did not gone out of campus with the intent of hooking up for sex. Whereas, the rest $74(36.8 \%)$ of them were gone out of campus with the intent of hooking up for sex.

Table-5: Respondents Sexual Experiences, Dire Dawa University, $2019(\mathbf{n}=\mathbf{2 0 1})$

\begin{tabular}{llll}
\hline Statements & $N$ & Yes & No \\
\hline Have had sexual intercourse after joining campus life & 201 & $81(40.3 \%)$ & $120(59.7 \%)$ \\
\hline Have had sexual intercourse with more than one partner & 201 & $45(22.4 \%)$ & $155(77.1 \%)$ \\
\hline Have had sex with a person who had more than one sexual partner & 201 & $76(37.8 \%)$ & $125(62.2 \%)$ \\
\hline In the past 12 months use of condom during sexual intercourse & 201 & $75(37.3 \%)$ & $126(62.7)$ \\
\hline Have you gone out of campus with the intent of hooking up for sex & 201 & $74(36.8 \%)$ & $127(63.2 \%)$ \\
\hline Have you had sex with that you didn't trust & 201 & $42(20.9 \%)$ & $159(79.1)$ \\
\hline Have you had vaginal inter course without a condom & 201 & $69(34.3 \%)$ & $132(65.7 \%)$ \\
\hline Have you had sex with a new partner before discussing sexual history & 201 & $75(37.3 \%)$ & $126(62.7)$ \\
\hline
\end{tabular}

Relationships between Khat Chewing Habits and Sexual Practices among Dire Dawa University Students The relationship between Khat chewing habits and sexual practices (as measured by sexual practice scale (SPS) and sexual experience scale (SES) was investigated using Pearson product-moment correlation coefficient. Preliminary analyses were performed to ensure no violation of the assumptions of normality, linearity and homoscedasticity. There is a positive correlation between students' khat chewing score and sexual practice, $r$ $=.774, n=201, p<.000$, with sexual experience, $r=.459, n=201, p<.000$, and there is also a positive correlation between sexual practices and sexual experiences, $r=.773, n=201, p<.000$.

Table-6: Pearson Correlations between Khat Chewing and Sexual Practice and Experiences, Dire Dawa University, $2019(\mathrm{n}=\mathbf{2 0 1})$

\begin{tabular}{lccc} 
Variables & 1 & 2 & 3 \\
\hline Khat Chewing & 1 & $.774^{* *}$ & $.459^{* *}$ \\
Sexual Practices & & 1 & $.773^{* *}$ \\
Sexual Experiences & & & 1 \\
\hline
\end{tabular}

**. Correlation is significant at the 0.01 level (2-tailed).

Sex Difference in Sexual Practice and Sexual Experience Scores

An independent-samples t-test was conducted to compare the sexual practice and sexual experience scores for males and females. There was significant difference in SPS scores for males $(M=12.71, S D=2.06)$ and females $(M=13.30, S D=1.77 ; t(201)=-.2 .171, p=.031$, two-tailed). But, there was no significant difference in SES scores for males $(M=13.24, S D=2.26)$ and females $(M=13.73, S D=2.03 ; t(201)=-.1 .610, p=.109$, twotailed). 
Table-7: Sex Difference in Sexual Practice and Sexual Experience Scores

\begin{tabular}{lllllll}
\hline Variables & Sex & $N$ & $M$ & $S D$ & $T$ & Sig. \\
\hline SPS & Male & 112 & 12.7143 & 2.06397 & & \\
& Female & 89 & 13.3034 & 1.77997 & -2.171 & $.031^{*}$ \\
SES & Male & 112 & 13.2411 & 2.26308 & & \\
& Female & 89 & 13.7303 & 2.03807 & -.1 .610 & .109 \\
\hline
\end{tabular}

*shows significant level at 0.05 SPS-Sexual Practice Scale SES-Sexual Experience Scale

\section{DISCUSSION}

The main purpose of this study was focus on the following three basic questions: what are the sexual practices and experiences of students in Dire Dawa University? What are the factors associated with Khat chewing habits among Dire Dawa University students? And is there any relationship between Khat chewing habits and sexual practices among Dire Dawa University students? As such, the findings of this study were presented as follow:

\section{Sexual Practices and Experiences among Dire Dawa University Students}

This study revealed that $66(32.8 \%)$ of students had sexual practice habits. This finding is higher than the findings from Jimma and Haramaya University, in which $(26.9 \%)$ and $(33.5 \%)$ of students ever had sexual intercourse, respectively (Tura G, Alemseged F, Dejene, S., 2012) and (Derese, A., Seme, A., \& Misganaw, C. 2014). The findings of this study revealed that the sexual practices of the respondents having sex with uncommitted partners $136(67.7 \%)$ was the higher response for sexual practices and sex before discussing risk factors $131(65.2)$ and Sex under the influence of khat chewing 82 (40.8\%). According to Kebede et al. (2018), study conducted on risky sexual behavior and practice among Aksum University students revealed that out of the total respondents, 174 $(60.6 \%)$ of students had sexual experience. From the total respondents who had practiced sexual intercourse 66 $(37.9 \%)$ of them reported that their first sexual intercourse was before age of 18 years while $89(51.2 \%)$ of them had their first sex at above or equal to 18 years. All of the respondents with sexual experience $174(100 \%)$ has practiced vaginal sex, followed by anal and oral in which 6.3 and 5.2\% respectively (Kebede et al., 2018).

Another similar study which conducted by Abayneh Unasho and Tarekegn Tadesse (2013), showed that among the respondents, about $355(28 \%)$ students reported to have had sexual intercourse. Forty three $(22.8 \%)$ reported to have had their first sexual intercourse after they joined the university. Among the students reported to have ever had sexual intercourse, $220(64.1 \%)$ had used a condom at least once and less than half (116, $32.7 \%$ ) had used condoms during their first sexual encounters. This findings was similar with current study shows that the sexual experiences of the respondents having sexual intercourse after joining campus life was 81 $(40.3 \%)$ and whereas the majority $120(59.7 \%)$ of them reported that they have sexual experiences before joining campus. Out of the total respondents, $155(77.1 \%)$ of students had no sexual intercourse with more than one partner whereas, $45(22.4 \%)$ of students had sexual intercourse with more than one partner (Abayneh Unasho and Tarekegn Tadesse, 2013).

\section{Factors Associated with Khat Chewing Habits among Dire Dawa University Students}

According to the current study by Abate et al. (2018) the prevalence of khat chewing in Bahir Dar City administration, Northwest Ethiopia, indicated that out of the total 794 study participants, 204 (25.7\%) had a history of chewing khat at least once in their life; of them, $79.9 \%$ had the history of chewing in the last 12 months. About 95 percent of those who chewed in the last 12 months practiced khat chewing within last 3 months. This study indicate that the reasons for khat chewing habits were revealed as to increase academic performance and religious practices were mentioned by $44.3 \%$ and $14.4 \%$ of study participants respectively. The reasons for chewing khat were different from the study conducted among Jimma University by Deribachew and Kanchi (2015) which reveal the major reason for khat chewing among students was to get concentration 50 (50.5\%) followed by relaxation 32 $(29.9 \%)$. On the other hand, reasons for practicing khat chewing as studied by Abate et al. (2018) were included fighting depressed mood and getting concentration were mentioned by 56.9 and $45.6 \%$ of study participants, respectively. According to Gemechis, T., Atinafu, K., Bedasa, T., Dagne, T. (2017), te past 12 months and current khat use among the regular undergraduate students of Dire Dawa University (DDU) were 59.9\% and 59.6\% respectively. This study also show that there is significantly correlated to khat chewing in past year among Dire Dawa University regular undergraduate students and state reasons for khat chewing as getting relief from stress and keeping alert were positively associated with khat chewing in past 12 months.

\section{Relationships between Khat Chewing Habits and Sexual Practices and Experiences}

There is a positive correlation between students' khat chewing score and sexual practice, $r=.774, n=201, p$ $<.000$, with sexual experience, $r=.459, n=201, p<.000$, and there is also a positive correlation between sexual practices and sexual experiences, $r=.773, n=201, p<.000$. This study also similar with the findings of Kebede Y. (2002), there is a strong link between chewing khat, taking excess alcohol, unsaved sexual practice among college students in North West Ethiopia. According to Endalew, G. (2014) find out that chewing khatwas found to be positively associated with premarital sexual practice among Unmarried First Year Undergraduate Students in Alkan University Collegein Addis Ababa. 
According to the study conducted by NASTAD (2013) regarding risk behaviors for HIV and STI among Dire Dawa University Students indicated that students were at higher risk for HIV/AIDS as a result of substance abuse or drug addiction such as khat, tobacco, shisha, hashish daily used by most students. Young people aged 15-24 years in Dire Dawa, Ethiopia, have a higher risk of HIV infection when compared to other regions of the country, and in 2009 , it was estimated that $2.5 \%$ of Dire Dawa University students were HIV positive. According to the research done in Dire Dawa Administration, the excessive use of alcohol and other substances (such as alcohol, khat, and tobacco products) was identified as the main factor for the prevalence of HIV infection among youths ( Kassa, Tadesse \& Yilma, 2014). Moreover, the study conducted by Abate et al. (2018) revealed that khat use was found to be a risk factor for the development of risky sexual behaviors exposing them at risk for acquisition and transmission of STIs.

\section{CONCLUSION}

The present study has identified the major issues regarding sexual practices, experiences and khat chewing habits among Dire Dawa University students. Based on the findings of the study, the following conclusions were made:

* The study shows that the sexual practices of the respondents having sex with uncommitted partners 136 (67.7\%) was the higher response for sexual practices and having sex before discussing risk factors 131 (65.2) and Sex under the influence of khat chewing $82(40.8 \%)$ were reported by the study participants. Regarding Sex without a condom 155 (77.1\%) revealed that no sex without condom whereas 46(22.9\%) of the respondents only did sex without a condom.

* The study shows that the sexual experiences of the respondents having sexual intercourse after joining campus life was $81(40.3 \%)$ and whereas the majority $120(59.7 \%)$ of them reported that they have sexual experiences before joining campus. Out of the total respondents, $155(77.1 \%)$ of students had no sexual intercourse with more than one partner whereas, $45(22.4 \%)$ of students had sexual intercourse with more than one partner. Surprisingly, in the past 12 months, $126(62.7 \%)$ of respondents did not use of condom during sexual intercourse and only 76 (37.8\%) of respondents use condom during sexual intercourse.

* The study participants stated a number of reasons for khat chewing habits such as to increase academic performance and religious practices were mentioned by $44.3 \%$ and $14.4 \%$ of study participants respectively.

* There is a positive correlation between students' khat chewing score and sexual practice, $r=.774, n=$ $201, p<.000$, with sexual experience, $r=.459, n=201, p<.000$, and there is also a positive correlation between sexual practices and sexual experiences, $r=.773, n=201, p<.000$. This study finding showed that from the total respondents about $77.1 \%$ and $22.9 \%$ of the respondents reported they had experienced chewing khat and no experience of chewing khat respectively.

\section{RECOMMENDATIONS}

Based on the findings of the study the following points were suggested:

$>$ Educators and counselors can facilitate educational and counseling interventions to help university students to interact without sexual risk behaviors and khat addictions.

$>$ Educational administrators, instructors, counselors and college deans had better introduce treatment and prevention strategies of sexually risky behaviors and drug addictions through counseling, training and support for students at risk during their studies/academic activities.

$>$ Moreover, sexually risky behaviors and drug addictions support programs, skill training and other awareness raising for university students should consider the impacts of sexual activities and khat chewing habits on students academic and social life's.

$>$ Teaching staff and college administrators also have to implement effective student support services, such as psycho-social advising, guidance and team work sprit between male and female students.

$>$ Furthermore, university based prevention centers for drug addiction and HIV/AIDS should established and support students to refrain from sexually risky behaviors.

\section{Future Implication for Research}

Since, the present research focused on to investigate sexual practices and khat chewing habits among second and third year university students, further research could be carried out across various public and private universities in Ethiopia. This study also gathered information from the students only regarding sexual practices and khat chewing habits, therefore future study can incorporate other non-student issue such as instructors, university administrator, school counselor and gender officers qualitatively in assessing sexual practices and khat chewing habits related issues in other settings such as high school and elementary school levels to strength the obtained data. 


\section{Limitations}

This study was limited to one college namely natural and computation science in Dire Dawa University. Combining various students across many fields of study in both public and private higher education institutions across the country may be helpful for generalization. The results from this university would not be sufficient to generalize the findings to all higher institutions in Ethiopia. In addition, there was no private university students incorporated in this study. The comparison was done between various fields of study and universities may have different results compared to students from natural and computation science.

\section{Acknowledgements}

I would primarily like to acknowledge Dire Dawa University administrators, college deans, department heads, registrar and second and third year students due to their welcome and assistance during data collection activities. Lastly but not least, I would like to acknowledge and thank our Social Psychology Ph. D. students, friends and colleagues who directly and indirectly contributed their effort for all activities in this research.

\section{Competing Interests}

This manuscript maintains no competing financial interest declaration from any person or institutions. I was conducting this research via my own personal interest with my pocket money. This research was conducted for the fulfillment of Ph.D. course work in areas of Social Psychology.

\section{Availability of Data and Materials}

The data sets used and analyzed during the current study available from the corresponding author on reasonable request.

\section{References}

Abate et al. (2018). Chewing khat and risky sexual behavior among residents of Bahir Dar City administration, Northwest Ethiopia. Ann Gen Psychiatry (2018) 17:26 https://doi.org/10.1186/s12991-018-0194-2

Abayneh Unasho and Tarekegn Tadesse. (2013). Assessment of potential risky sexual behaviors among Dilla University students: A survey study for enhancing self- protection from human immunodeficiency virus (HIV) infection. Journals of AIDS and HIV Research,Vol. 5(7), pp. 235-248, July, 2013 DOI 10.5897/JAHR12.071

CDC. (2012). Serological and behavioral survey of students attending secondary schools in hotspot woredas with the Amhara Regional state.

Derese, A., Seme, A., \& Misganaw, C. (2014). Assessment of Substance Use and Risky Sexual Behavior among Haramaya University Students, Ethiopia. Science Journal of Public Health, 2(2), 102-110. doi: 10.11648.j.sjph.20140202.19

Ethiopia Demographic and Health Survey (EDHS). (2005). Addis Ababa, Ethiopia: Central Statistical Agency and ORC Macro; 2005.

Deribachew Hailemariam and Kanchi. Madhavi .(2015). Prevalence of Khat abuse and associated factors among undergraduate students of Jimma University, Ethiopia. Int J Res Med Sci. 2015 Jul;3(7):1751-1757

Endalew, G. (2014). Premarital Sexual Practice among Unmarried First Year Undergraduate Students in Alkan University College in Addis Ababa, Ethiopia.

Global Journal of Medicine and Public Health, GJMEDPH 2014; Vol. 3, Issue 2.

Gemechis, T., Atinafu, K., Bedasa, T., Dagne, T. (2017). Psycho-active Substances Use and Determining Factors Among Regular Undergraduate Students of Dire-Dawa University,

Eastern Ethiopia. Science Journal of Public Health. Vol. 5, No. 2, 2017, pp. 68-76. doi: 10.11648/j.sjph.20170502.13

Habtamu Teklie et al. (2017). Prevalence of Khat chewing and associated factors in Ethiopia: Findings from the 2015 national Non-communicable diseases STEPS survey. Ethiop. J. Health Dev. 2017;31(Special Issue)

Kassa, A. Tadesse, F. Yilma, A. (2014). Prevalence and factors determining psychoactive substance (PAS) use among Hawassa University (HU) undergraduate students, Hawassa Ethiopia. BMC Public Health 2014, 14:1044.

Kebede et al. (2018). Assessment of risky sexual behavior and practice among Aksum University students, Shire Campus, Shire Town, Tigray, Ethiopia. BMC (2018) 11:88

Kebede, Y. (2002). Cigarette smoking and khat chewing among college students in North West Ethiopia. Ethiopian Journal of Health Development2002, 16:9-17.

NASTAD. (2013). Assessment of Risk Behaviors for HIV and STI among Dire Dawa University Students. National Alliance of State \& Territorial AIDS Directors, 444 North Capitol Street NW, Suite 339, Washington, D.C. 20001-1512 (202) 434-8090.

Numan, N. (2012). The Green Leaf: Khat. World Journal of Medical Sciences, 2012; 7 (4): 210-223. 
Rahel, etal. (2003) patterns and correlates of sexual initiation, sexual risk behaviors and condom use among secondary school students in Ethiopia. Ethiopian medical Journal, 41(2), 163-77

Strong, B. (2005). Human sexuality Diversity in contemporary America New York: Mc grew- Hill companies, Inc. Turchik, J. A. and Garske, J. P. (2008), Measurement of Sexual Risk Taking Among College Students. Arch Sex Behav. DOI 10.1007/s10508-008-9388-z

Tura G, Alemseged F, Dejene, S., (2012). Risky sexual behavior and predisposing factors among students of Jimma University, Ethiopia. Ethiop J Health Sci. 2012;22(3):170-80. 